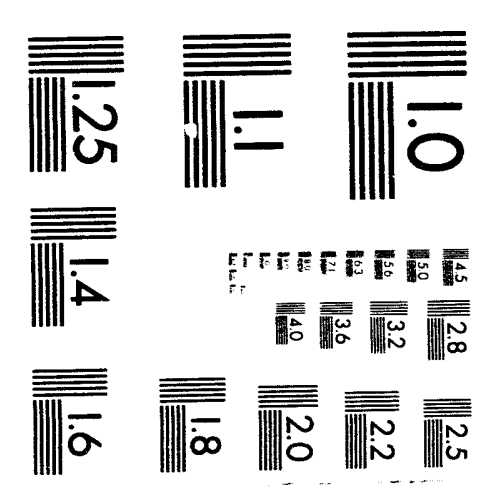



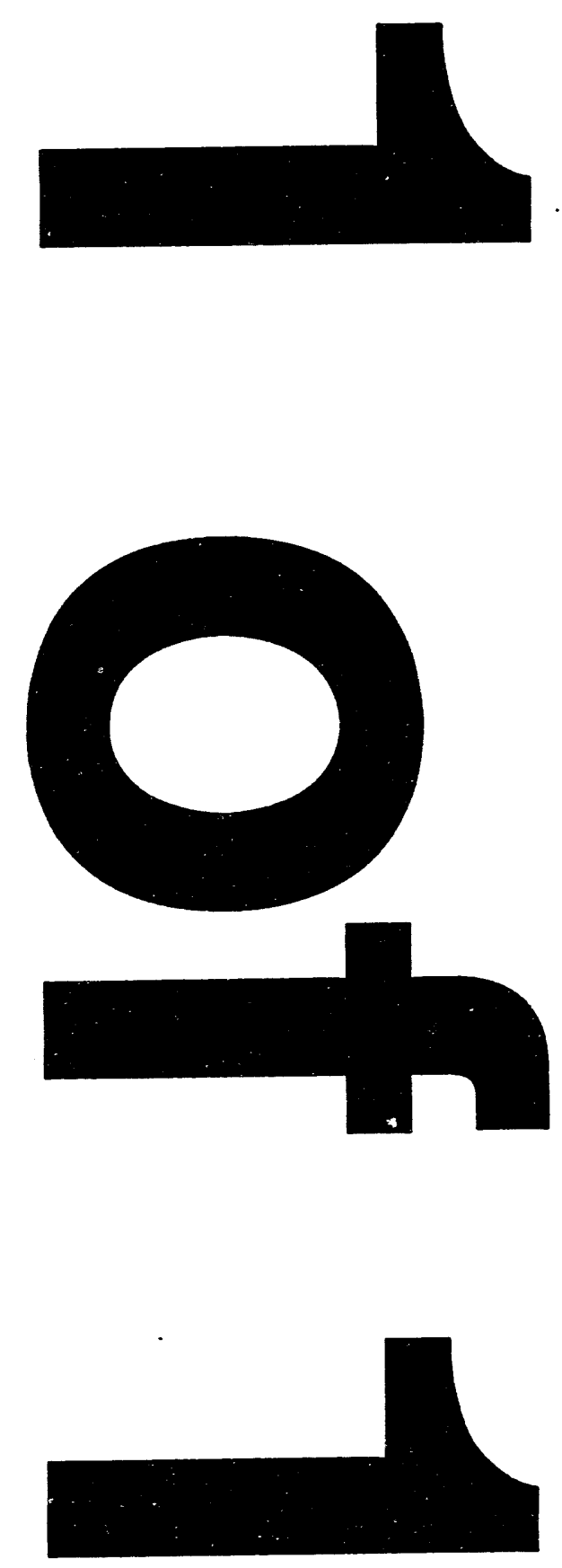


\title{
DOE/PC/89783 - -TTY
}

Quarterly Progress Report for the period 04/01/91 - 06/30/91

\author{
to the US Department of Energy
}

Project title:

Projest number:

Principal Investigator:

Date of report:
"Fundamental Studies of Catalytic
Processing of Synthetic Liquids"

DE-FG22-89PC89783

Prof. Philip R. Watson

Department of Chemistry and Center for Advanced Materials Research Oregon State University Gilbert Hall 153

Corvallis, OR 97331-4003

(503)-737-2081

$06 / 24 / 91$

\section{DISCLAIMER}

This report was prepared as an account of work sponsored by an agency of the United States Government Neither the United States Government nor any agency thereof, nor any of their employees, makes any warranty, express or implied, or assumes any legal liability or responsibility for the accuracy, completeness, or usefulness of any information, apparatus, product, or process disclosed, or represents that its use would not infringe privately owned rights. Reference herein to any specific commercial product, process, or service by trade name, trademark, manufacturer, or otherwise does not necessarily constitute or imply its endorsement, recommendation, or favoring by the United States Government or any agency thereof. The views mendation, or favoring by the Unions of authors expressed herein do not necessarily state or reflect those of the United States Government or any agency thereof.

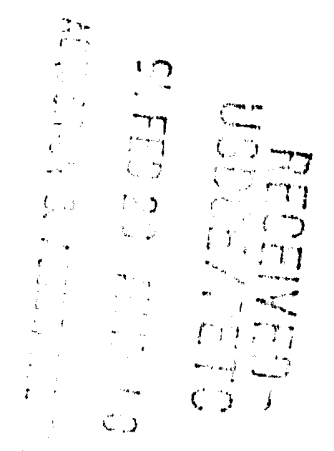




\section{Background}

This project revolves around understanding the fundamental processes involved in the catalytic removal of harmful oxygenated organics present in coal liquids. We are modelling the complex type of sulfided Mo catalyst proposed for these reactions with simple single crystal surfaces. These display a controlled range and number of reaction sites and can be extensively characterized by surface science techniques. We then investigate the reaction pathways for representative simple oxygenates upon these surfaces.

\section{Summary}

In order to better understand the nature of the active surface in these experiments we have recorded low energy diffraction (LEED) data from the $p(2 \times 2)$ structure formed by sulfur on $\mathrm{Mo}(110)$. We have compiled a large number of intensity-voltage (IV) curves and have started the process of solving the surface structure using the new Tensor LEED method.

Our previous work has shown that an important component of furan reactions on sulfided Mo surfaces are dehydrogenation reactions of adsorbed hydrocarbon fragments. The desorption of hydrogen occurs in several steps and is strongly influenced by the amounts of sulfur and carbon on the surface. In order to understand this complex behavior during this period we commenced a series of adsorption/desorption experiments for hydrogen (deuterium) on $\mathrm{Mo}(110)$. These experiments will be performed on both the clean surface and surfaces that have been prepared with varying amounts of carbon and sulfur on the surface. The first data from 
the clean surface are in good agreement with earlier literature reports.

3. Progress

a) TLEED investigation of the sulfided Mo(110)

Am important concern in this work is the nature of the likely adsorption site for furan on the sulfided Mo surfaces. Although the phase diagram for the Mo(110)-S system is well known [1], the details of the location of the $S$ adatom and atomic arrangement, or rearrangement, of the underlying metal adatoms are not understood. Therefore we have embarked upon collecting LEED data from the $p(2 \times 2)-S$ structure that has played a large role in our investigations. We will use the latest tensor LEED (TLEED) codes [2] to determine the surface structures.

The $\mathrm{p}(2 \times 2)-S$ structure was generated by adsorbing a saturation amount of $S$ on a Mo(110) surface from an electrochemical source and then annealing to form the $0.25 \mathrm{ML}$ $p(2 \times 2)-S$ structure as described in previous reports. We have recorded a total of $13 \mathrm{I}(\mathrm{V})$ curves at normal incidence and a similar number of off-normal beams at $208 \mathrm{~K}$ using new data analysis software that we have developed [3]. The beam locations are shown in Figure 1. At present the TLEED codes can only handle normal incidence.

Figures 2-5 shows a selection of the $\mathrm{I}(\mathrm{V})$ curves for some integral and half-order beams at normal incidence. Work has started on running the programs to best fit this data to a structure.

b) Adsorption/desorption of hydrogen on clean $\mathrm{Mo}(110)$

We have started a series of experiments to probe hydrogen adsorption/desorption kinetic on sulfided Mo surfaces. In order to obtain better signal to noise ratios the 
experiments have actually employed deuterium. Our experience with other systems has shown that deuterium TDS is almost identical to hydrogen TDS and we shall refer to deuterium and hydrogen interchangeably. Our first data has been obtained for the clean Mo(110) surface.

Figure 6 shows a series of deuterium thermal desorption spectroscopy (TDS) traces after various exposures of $\mathrm{Mo}(110)$ to deuterium. Our data is very similar to that of Mahnig and Schmidt [4]. The small differences in peak temperature and shape can be attributed to the slower heating rate in our case. At 10L exposure to hydrogen the amount of material that desorbs, as measured by the area under the TDS curve, is unchanged. This indicates that the surface is saturated at this point. The saturation coverage hydrogen cannot be directly measured from these experiments, but it can be estimated. Mahnig and Schmidt [4] found that the maximum hydrogen TDS yield from $\operatorname{Mo}(110)$ was just $1 / 2$ of that from $\mathrm{Mo}(100)$ Zaera et al [5] have shown that on $\mathrm{Mo}(100)$ the saturation coverage of hydrogen corresponds to $2 \mathrm{H} / \mathrm{Mo}$. Hence we expect the saturation coverage of hydrogen on $\mathrm{Mo}(110)$ to be $1 \mathrm{H} / \mathrm{Mo}$. Given the close agreement between our data and that of Mahnig and Schmidt, we therefore will assume that the saturation coverage that occurs at about $10 \mathrm{~L}$ exposure corresponds to a hydrogen coverage equal to $1.0 \mathrm{ML}$.

\section{Future Work}

Research during the next quarter will concentrate on the following:

i) solving the $\mathrm{Mo}(110) \mathrm{p}(2 \times 2)-\mathrm{S}$ structure

ii) extending the hydrogen TDS studies to Mo surfaces that are predosed with $S$ and $C$ 


\section{References}

1. A. Sanchez, J.J. de Miguel, E. Martinez and R. Miranda, Surf. Sci. 171157 (1986).

2. TLEED Codes by M.A. Van Hove, P.J. Rous and M. Wander, Lawrence Berkeley Laboratory.

3. J. Toofan and P.R. Watson, manuscript in preparation

4. M. Mahnig and L.D. Schmidt, Z. fur Physik. Chem. NF 80,71 (1972).

5. F. Zaera, E.B. Kollin and J.L. Gland, Surf. Sci. 166, L149 (1986). 
Figures:

1. Beams for which $I(V)$ curves have been recorded in the $M o(110) p(2 \times 2)-S$ system.

2. $\mathrm{I}(\mathrm{V})$ curves taken at normal incidence and $208 \mathrm{~K}$ for $(01),(-1,-1)$ and $(-1,1)$ beams.

3. I(V) curves taken at normal incidence and $208 \mathrm{~K}$ for (21), (20) and (22) beams .

4. $I(V)$ curves taken at normal incidence and $208 \mathrm{~K}$ for $(-1,0.5),(-1,-0.5)$ and $(1.5,1)$ beams.

5. $\quad I(V)$ curves taken at normal incidence and $208 \mathrm{~K}$ for $(2,0.5),(-0.5,0.5),(-1.5,0.5)$ and $(1.5,1.5)$ beams .

6. Thermal desorption of deuterium from clean $\mathrm{Mo}(110)$ for various exposures to $\mathrm{D}_{2}$. 
Figure 1

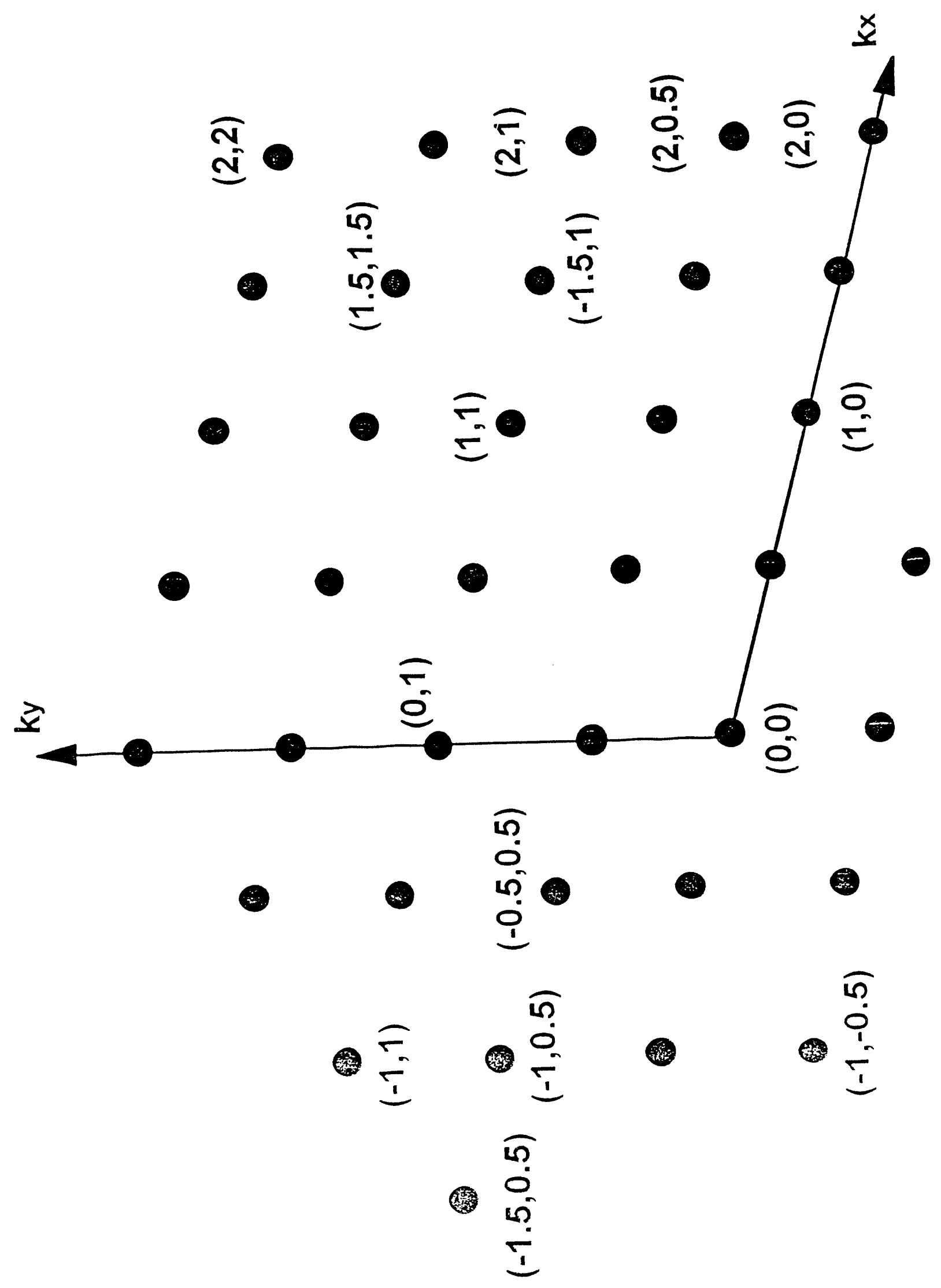




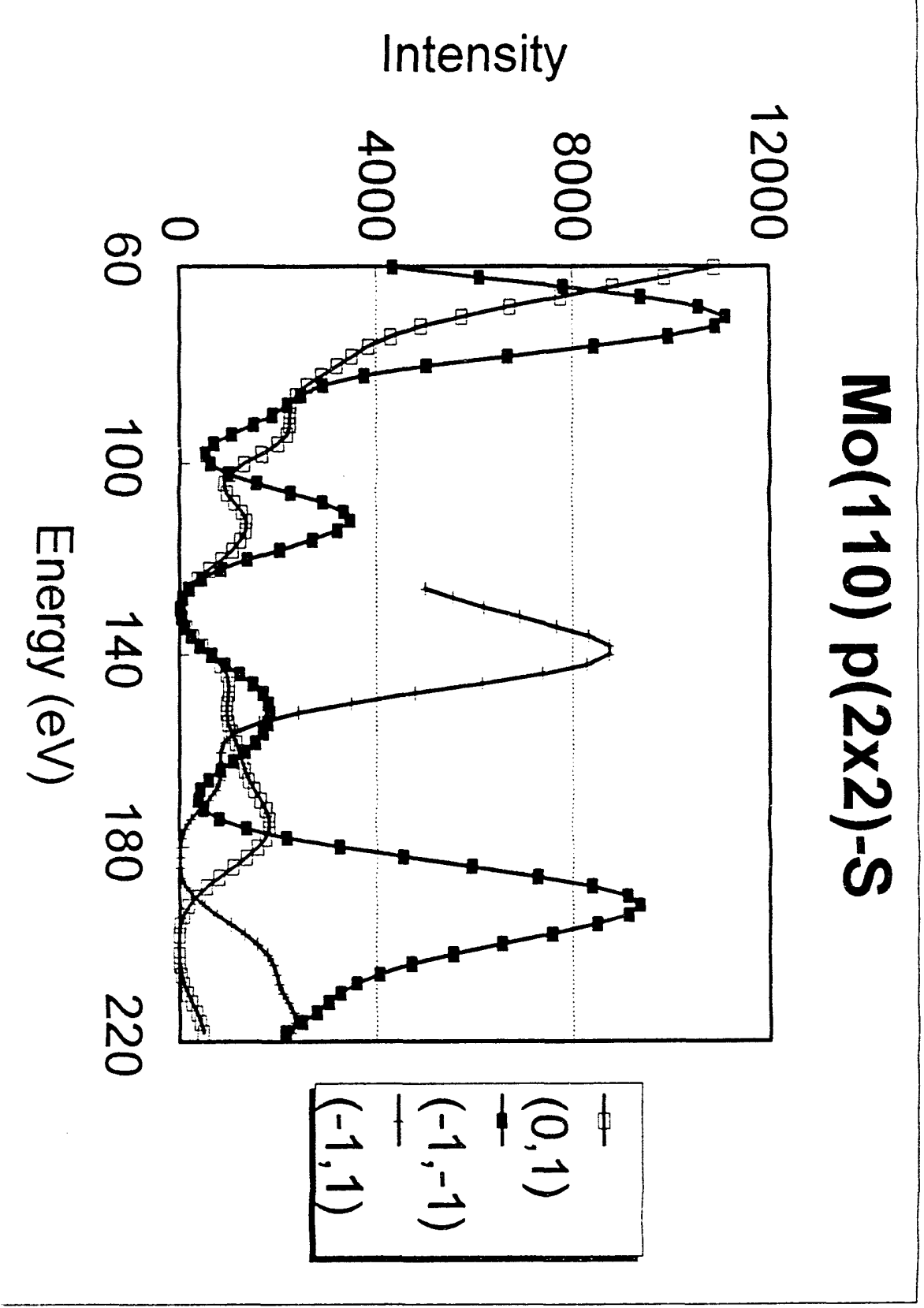


Figure 3

\section{$M o(110) p(2 \times 2)-S$}

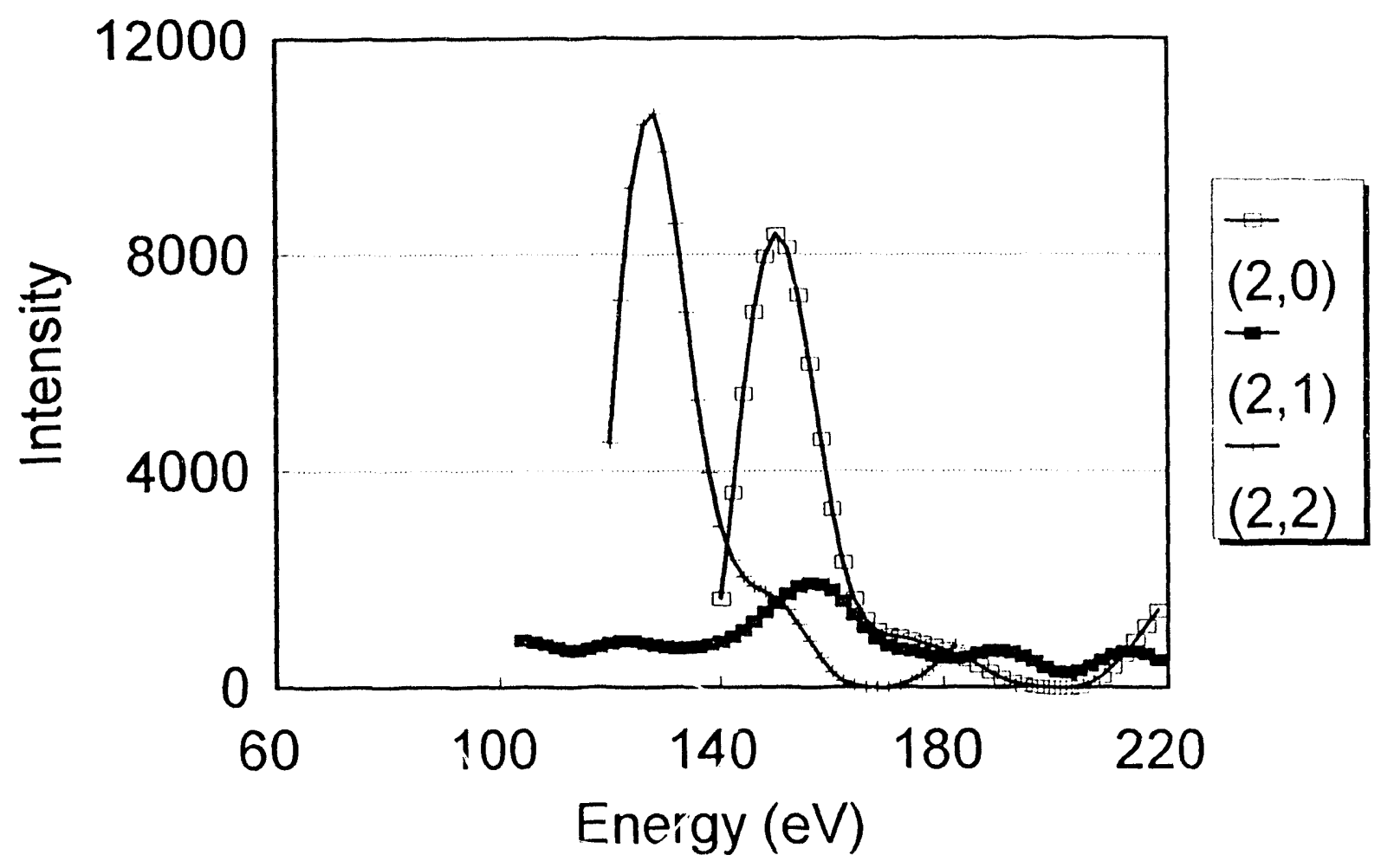




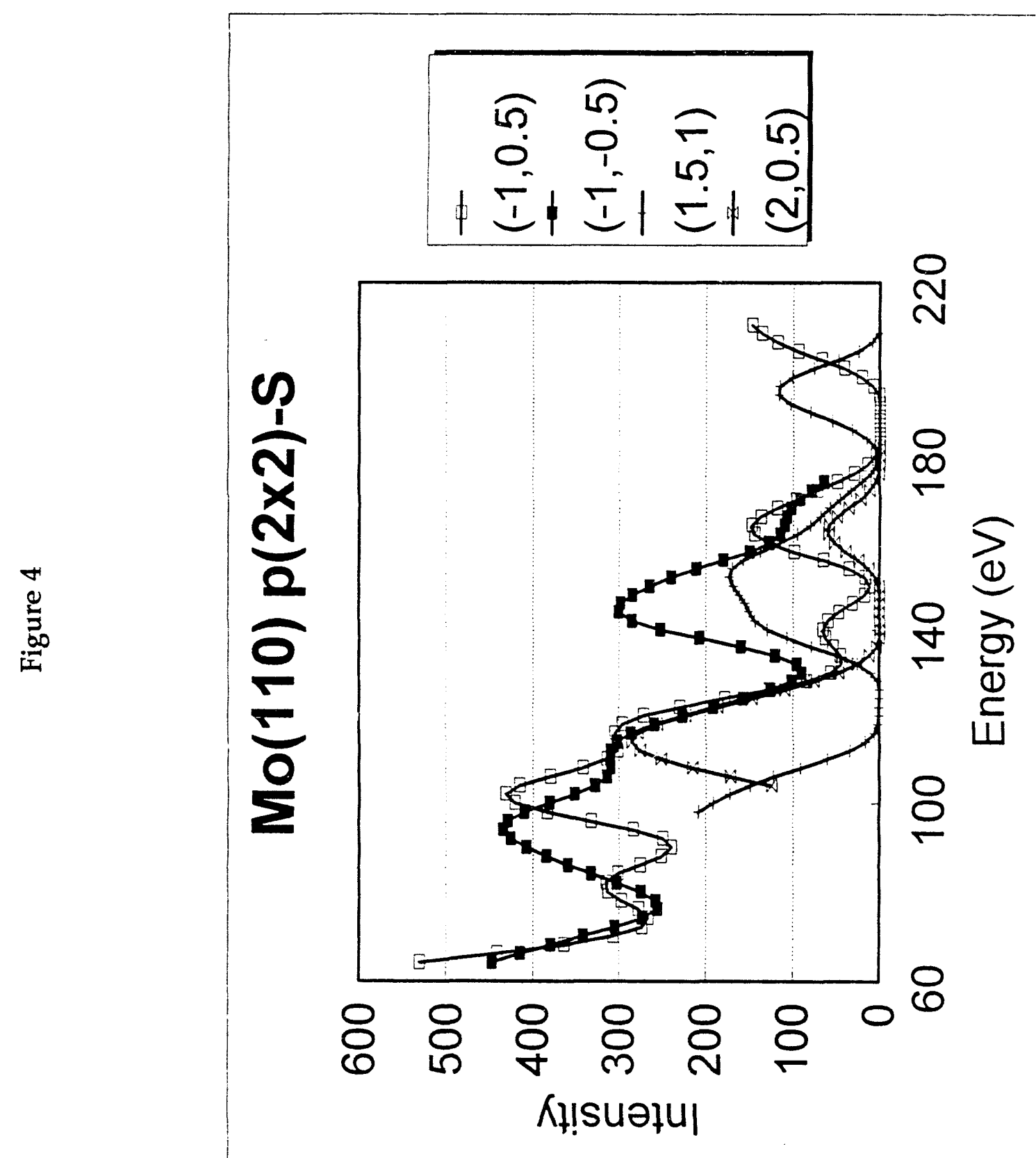


Figure 5

\section{$M o(110) p(2 \times 2)-S$}

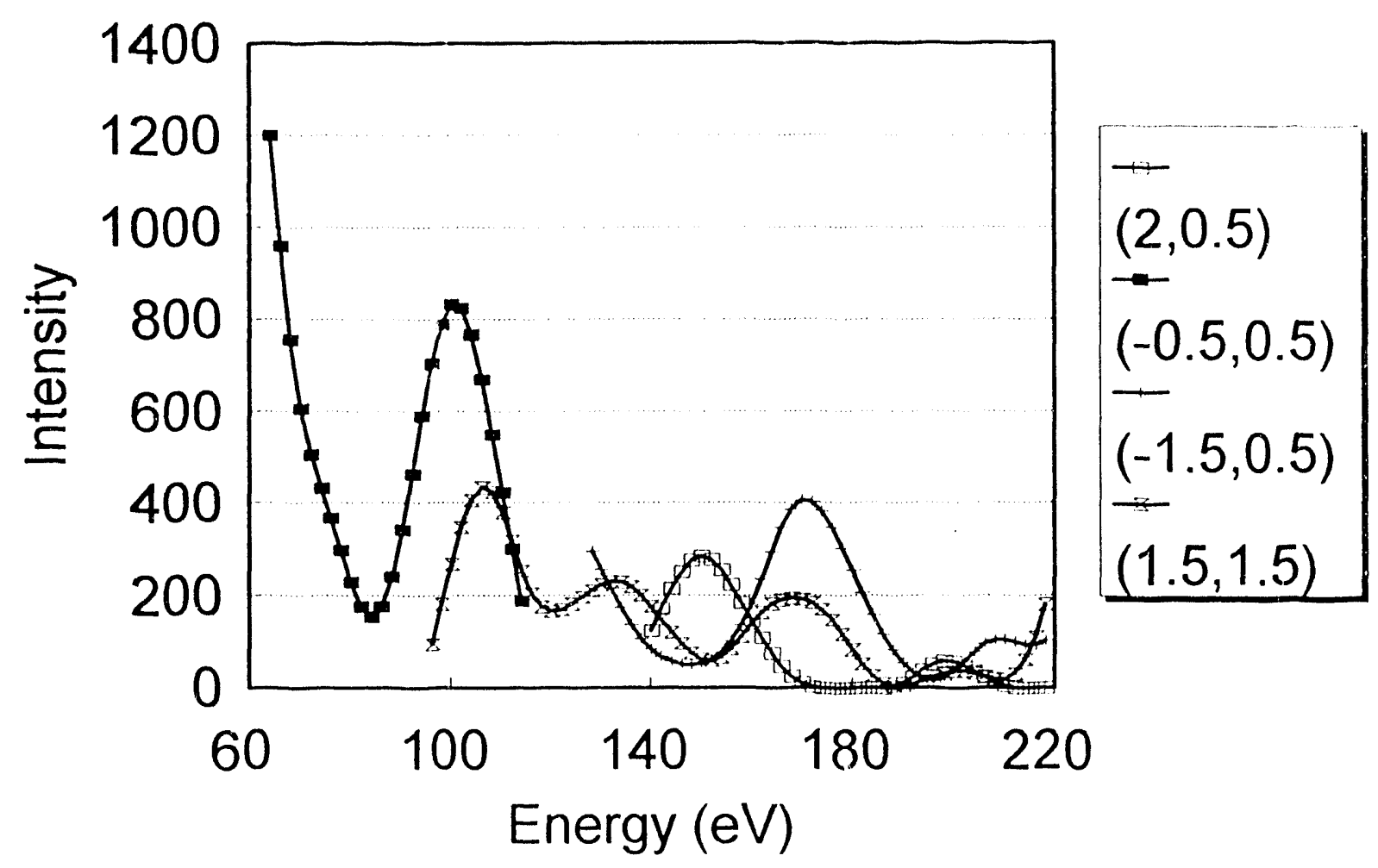


Figure 6

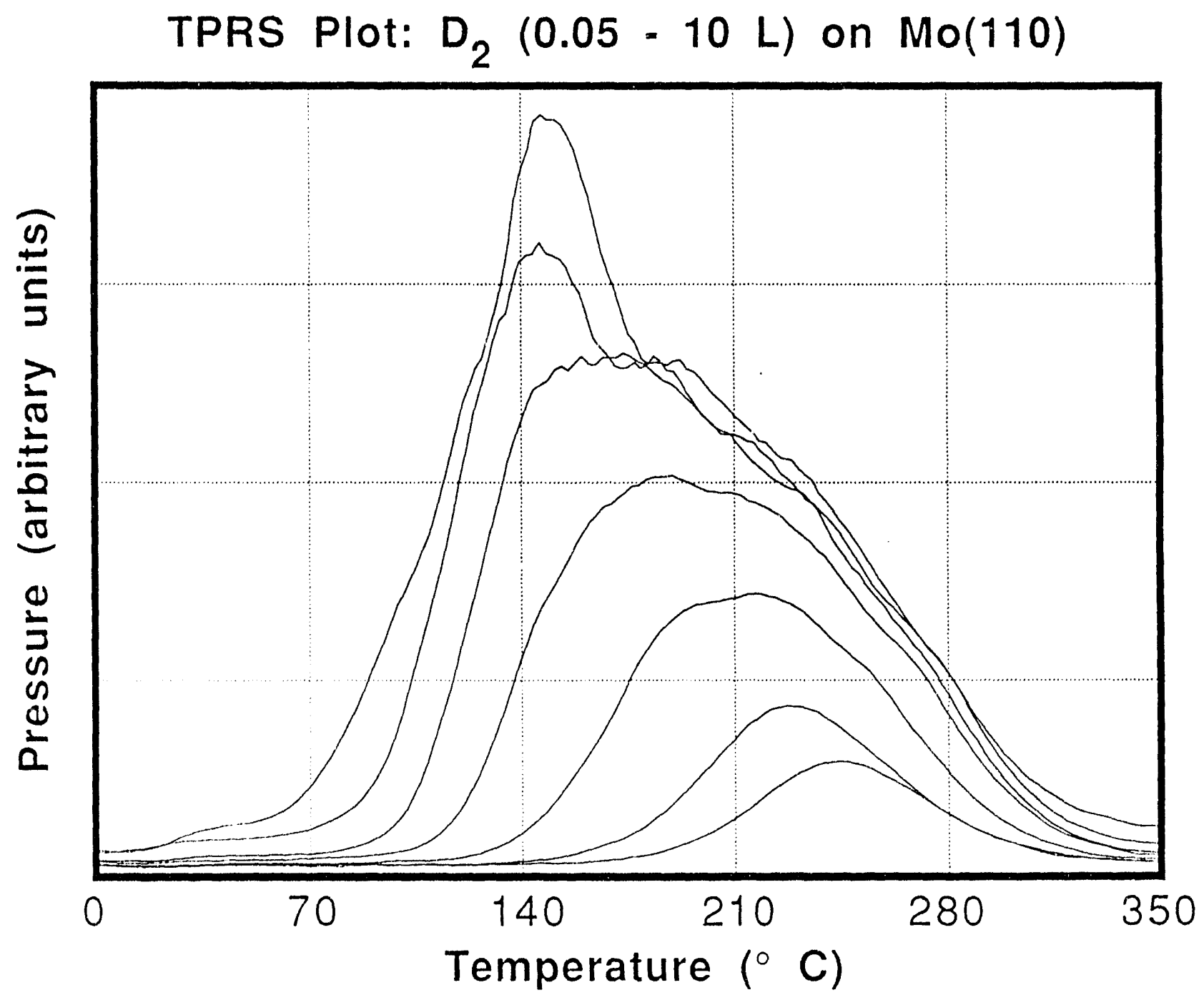



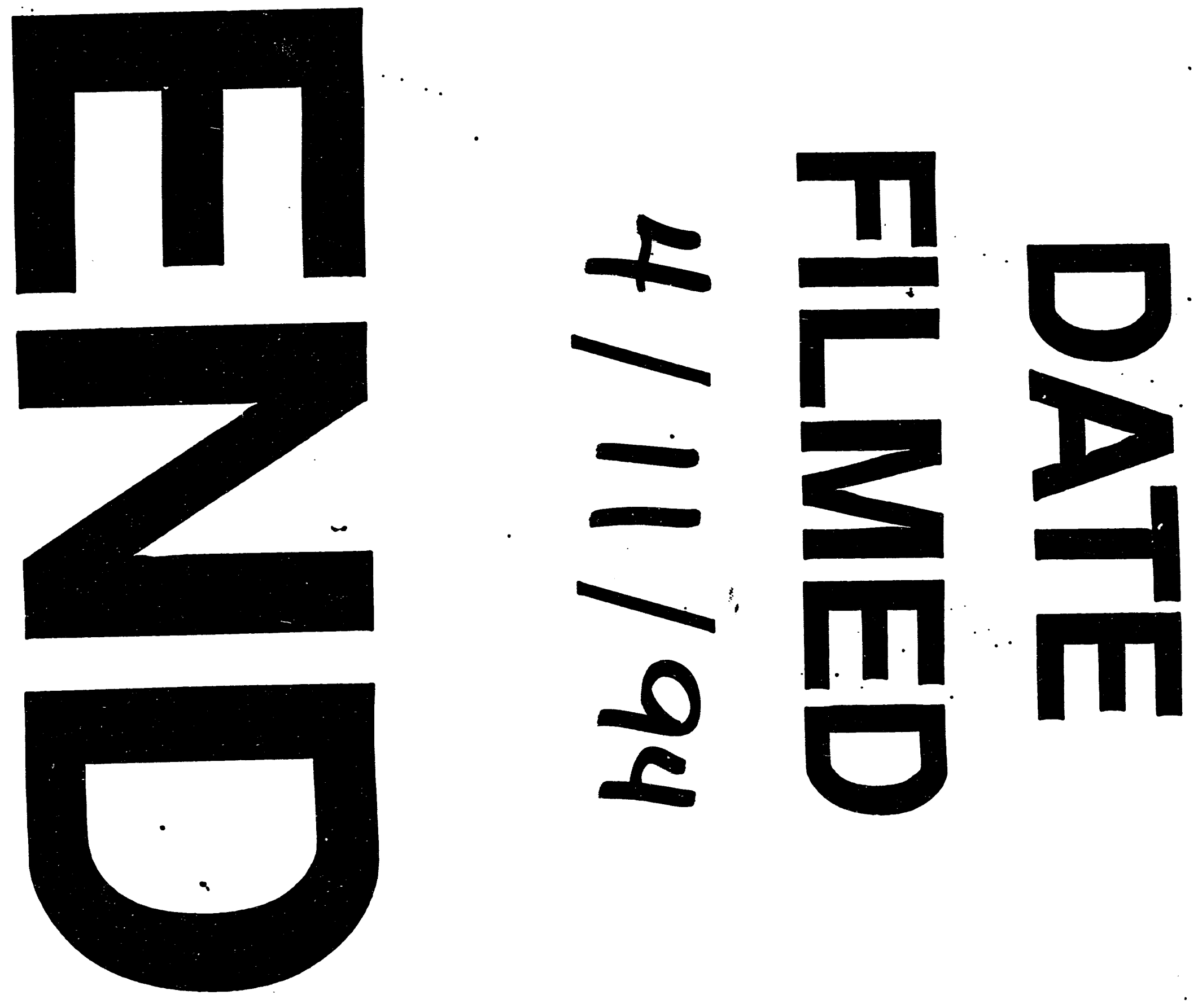


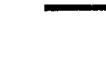
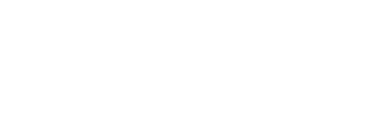